\title{
Patlıcan fidelerine yapılan UV-B ışın uygulamalarının fidelerde bitki besin maddesi içeriğine etkisi
}

\section{Effects of UV-B irradiation on plant nutrient contents of eggplant seedlings}

\author{
Serkan CANBAY ${ }^{1}$, Ersin POLAT ${ }^{2}$ (D) \\ ${ }^{1}$ Antalya Gıda Kontrol Laboratuvar Müdürlüğü, 07260 Kepez/Antalya \\ ${ }^{2}$ Akdeniz Üniversitesi, Ziraat Fakültesi, Bahçe Bitkileri Bölümü, 07070 Antalya \\ Sorumlu yazar (Corresponding author): S. Canbay, e-posta (e-mail): serkancnby@gmail.com \\ Yazar(lar) e-posta (Author e-mail): polat@akdeniz.edu.tr
}

\section{MAKALE BİLGİSI}

Alınıs tarihi 03 Mayıs 2020

Düzeltilme tarihi 08 Ekim 2020

Kabul tarihi 09 Ekim 2020

\section{Anahtar Kelimeler:}

Solanum melongena $\mathrm{L}$.

UV-B

Bitki besin maddesi

$\mathrm{H}_{2} \mathrm{O}_{2}$

\begin{abstract}
$\ddot{\mathbf{O Z}}$
Bu çalıșmada, Ultraviyole B (UV-B) 1șın uygulamalarının patlıcan fidelerinde bitki besin maddesi içeriğine olan etkileri araştırılmıştır. Bu amaçla patlıcan (Solanum melongena L. cv. Anamur $F_{1}$ ) fideleri, kontrol $\left(0 \mathrm{~kJ} \mathrm{~m}^{-2}\right.$ gün$\left.^{-1}\right), 10.8 \mathrm{~kJ} \mathrm{~m}^{-2}$ gün ${ }^{-1}$ (düşük doz) ve $16.2 \mathrm{~kJ} \mathrm{~m}^{-2}$ gün$^{-1}$ (yüksek doz) UV-B ışın uygulamasına ilk gerçek yapraklı oldukları dönemden itibaren 10 gün (sırasıyla, $76.5 \mathrm{dk}$ gün$^{-1}$ ve $114.75 \mathrm{dk}$ gün$^{-1}$ ) süre ile tabi tutulmuşlardır. Araştırmada fide köklerinde ve toprak üstü aksamda azot, potasyum, fosfor, kalsiyum, demir, magnezyum, mangan ve çinko içerikleri ile yapraklardaki $\mathrm{H}_{2} \mathrm{O}_{2}$ miktarı belirlenmiştir. Yüksek doz UV-B uygulamasının patlıcan fide köklerinde fosfor içeriğinin artışına sebep olduğu, düşük doz UV-B uygulamasının ise üst aksam fosfor içeriğini azaltırken, kök ve üst aksamlarda çinko miktarını arttırdığı, azot miktarındaki artışın ise sadece üst aksamda olduğu görülmüştür.
\end{abstract}

\section{ARTICLE INFO}

Received 03 May 2020

Received in revised form 08 October 2020

Accepted 09 October 2020

\section{Keywords:}

Solanum melongena $\mathrm{L}$

UV-B

Plant nutrient

$\mathrm{H}_{2} \mathrm{O}_{2}$

\begin{abstract}
The aim of the study was to investigate the effects of UV-B irradiation on plant nutrient contents in eggplant (Solanum melongena L) seedlings. Seedlings were subjected to UV-B irradiation $0 \mathrm{~kJ} \mathrm{~m}^{-2}$ day $^{-1}, 10.8 \mathrm{~kJ} \mathrm{~m}^{-2}$ day $^{-1}$ and $16.2 \mathrm{~kJ} \mathrm{~m}^{-2}$ day ${ }^{-1}$ for 10 days (76.5 min day-1 $114.75 \mathrm{~min}^{\mathrm{day}}{ }^{-1}$ ) when they reached to the first true leaves stage. In the study, nitrogen, potassium, phosphorus, calcium, iron, magnesium, manganese and zinc contents in the seedling roots and upper parts of seedlings and the amount of $\mathrm{H}_{2} \mathrm{O}_{2}$ in the leaves were determined. It has been determined that high-dose UV-B application causes an increase in phosphorus content in eggplant seedling roots, while low-dose UV-B application increases the amount of zinc in the root and upper parts. The increase in the amount of nitrogen by low-dose UV-B application was obserbed only in the upper part of seedlings.
\end{abstract}

\section{Giriş}

Güneşten yayılan enerji, fotosentez yoluyla dünya üzerindeki hayatın hemen hemen tamamının var olmasını sağlayan en önemli kaynaktır. Dünyaya güneşten gelen 1şınlardan dalga boyları 4000-3150 $\mathrm{A}^{\circ}$ arasında olan "UV-A" 1şınları dalga boyları 3150-2800 $\mathrm{A}^{\circ}$ arasında olan "UV-B" 1şınları, dalga boyları $2800 \mathrm{~A}^{\mathrm{o}^{\prime}}$ dan küçük olan "UV-C" 1şınları olarak adlandırılırlar. Yeryüzüne gelen toplam 1şıkların yaklaşık $\% 39$ 'u dalga boyları 4000-7000 $\mathrm{A}^{\circ}$ arasında olan ve gözle görülebilen, $\% 60$ kadarı dalga boyu $7000 \mathrm{~A}^{\circ}$ dan büyük olan ve $\% 1$ kadarı da dalga boyu $4000 \mathrm{~A}^{\mathrm{o}}$ dan küçük olan 1şıllardan oluşmaktadır. Ozon tabakası Ultraviyole radyasyonu için koruyucu bir bariyerdir. Ozon tabakasındaki incelme, yeryüzüne ulaşan UV-B radyasyon düzeyinde artışa yol açmakta ve bu da biyolojik ve kimyasal süreçleri olumsuz yönde etkilemektedir.
Güneşten kaynaklanan UV-B ya da yakıcı UV ıșınları, atmosferin toplam ozon içeriğindeki değişimlere karşı çok hassastır. Ozondaki her \%1'lik azalma, biyosfere ulaşan UV-B 1şınında \%1.3-1.8'lik artışa sebep olmaktadır (Anderson ve ark. 1991)

Stres, bitkisel üretimde biyotik ve abiyotik kökenli faktörler nedeniyle bitkinin büyüme ve gelişmesinde yavaşlama ve bunların sonucunda ise verim düşüklüğü ile sonuçlanan bir dizi gerileme olarak nitelendirilebilmektedir (Yaşar 2003). Süperoksit ve $\mathrm{H}_{2} \mathrm{O}_{2}$ gibi reaktif oksijen türlerinin (ROS) üretimi, abiyotik stres altındaki bitkilerin en yaygın tepkisi olarak kabul edilir. Yüksek ROS seviyeleri protein ve lipid peroksidasyonuna, klorofilin bozulmasına ve programlanmış hücre ölümüne neden olabilmektedir (Li ve ark. 2015). 
Çinko katkılı gübrelerin ya da uygulamalarının farklı bitki türlerinde verim ve kalite artışlarında olumlu etki gösterdiğinin birçok çalışma desteklemektedir. Çinko katkılı gübrelerin katkısızlara göre; karpuzda \%24, brokkoli de $\% 35$, marul baş ağırlığında \%20 oranında verim artışları sağladığı bildirilmektedir (Oktay 1999).

Verimi arttırmak hem de kaliteli bir ürün elde etmek için kaliteli bir fide ile üretime başlamak oldukça önemlidir. Pişkin ve kuru maddece zengin olan fidelerin tümü aynı büyüklükte ve gelişme hızında olmalıdır (Vural ve ark. 2000).

Fide işletmelerinde pişkin fide üretimi bitki gelişim düzenleyiciler ya da iklimsel faktörler (sıcaklık, 1şık, nem vs.), sulama ve gübreleme dengelerini değiştirmek gibi çeşitli teknikler kullanarak yapılmaktadır. $\mathrm{Bu}$ çalışma; patlıcan fidelerine uygulanan farklı dozlardaki UV-B ışın uygulamalarının fidelerde büyüme ve gelişmeye olan etkisine katk1 sağlayan bitki besin maddesi içeriklerini saptamak amacıyla yapılmıştır.

\section{Materyal ve Yöntem}

$\mathrm{Bu}$ çalışma, Akdeniz Üniversitesi Ziraat Fakültesi Bahçe Bitkileri Bölümünde cam serada yürütülmüştür. Araştırmada, deneme materyali olarak, Antalya il sınırları içerisindeki ticari bir fide üreticisinden sağlanan patlıcan (Solanum melongena $\mathrm{L}$. cv. Anamur $\mathrm{F}_{1}$ ) fideleri kullanılmıştır.

Fideler, kontrol dahil olmak üzere 3 gruba ayrılmış ve ilk iki grup, stratosferik ozon tabakasındaki $\% 20$ ve \%25'lik incelmeye karşılık gelebilecek doz için sırasıyla 4.25 ve 5.31
kJ m ${ }^{-2}$ gün $^{-1}$ olarak uygulayan Yuan ve ark. (1998)'nın belirttiği değerler referans alınmıştır. Buna göre çalışmada etkisi görülmek istenen uygulama dozları $10.8 \mathrm{~kJ} \mathrm{~m}^{-2}$ gün$^{-1}$ (düşük doz) ve $16.2 \mathrm{~kJ} \mathrm{~m}^{-2}$ gün $^{-1}$ (yüksek doz) olarak belirlenmiştir. Üçüncü grup fidelere ise UV-B ışını uygulanmamış, bu grup kontrol olarak denemede yer almıştır. Sistem, lambaların bitkiler üzerinde farklı yüksekliklere ayarlanmasına imkan verecek şekilde dizayn edilmiştir. UV-B ışın uygulamaları 311 $\mathrm{nm}$ dalga boyunda 1şın yayan ve $25 \mathrm{~mm}$ çapında dar band UV-B lambalar (Philips TL 100W/01 UV-B) ile gerçekleştirilmiştir. Belirtilen dozların ayarlaması, Watt $\mathrm{x}$ saniye $=$ Joule formülünden yararlanılarak hesaplanmış ve uygulamaya konulmuştur. İlk uygulamada doz ayarlaması dijital radyometrenin 0 değeri ölçtüğü akşam saatinde, UV-B lambası açılmış ve sensör lambadan $25 \mathrm{~cm}$ altta olacak şekilde tutularak yaklaşık 10 farklı noktadan ölçümler yapılmıştır. Radyometrede okunan ortalama $240 \mu \mathrm{W} \mathrm{cm}{ }^{-2}\left(2.40 \mathrm{~W} \mathrm{~m}^{-2}\right)$ değeri formülde yerine konulduğunda lambalar; $10.8 \mathrm{~kJ} \mathrm{~m}^{-2}$ gün-1 için $76.5 \mathrm{dk}$, $16.2 \mathrm{~kJ} \mathrm{~m}^{-2}$ gün$^{-1}$ için $114.75 \mathrm{dk}$ çalıştırılarak uygulama yapılacak dozlar hesaplanmıştır. Fidelere ilk gerçek yapraklı oldukları dönemde bitki tepe noktasının $25 \mathrm{~cm}$ üstüne lambalar yerleştirilerek 10 gün süre ile UV-B 1şın uygulaması yapılmıştır. Uygulama süresi boyunca hastalık ve zararlılara karşı herhangi bir bitki koruma ürünü kullanılmamış ve gübreleme yapılmamıştır.

Uygulamaların yapıldığı 13-22/05/2017 tarihleri arasında cam sera gece ve gündüz ortalama sıcaklık (Şekil 1) ve nem (Şekil 2) değerleri elektronik veri kaydedici olan Onset-HOBO ölçüm cihazı ile yapılmıştır.

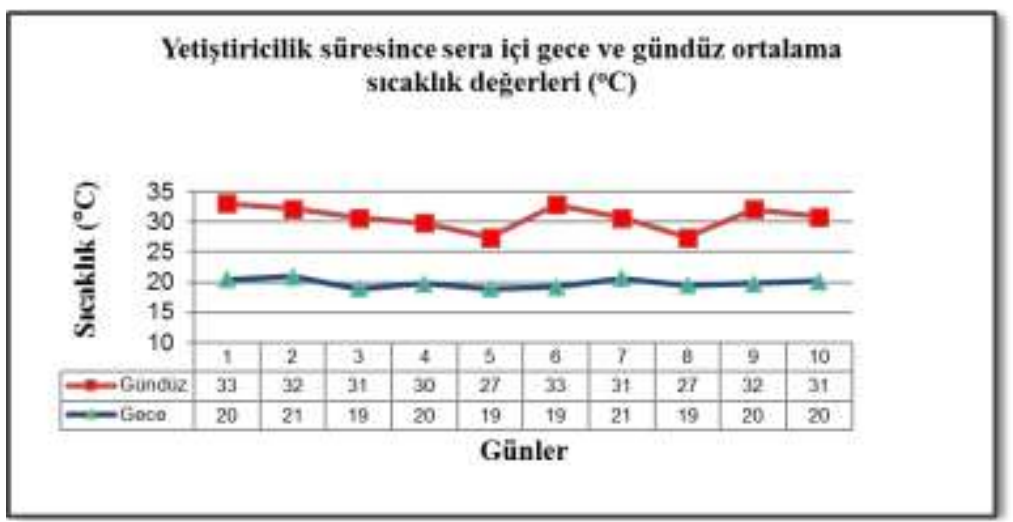

Şekil 1. Uygulamaların yapıldığı 13-22/05/2017 tarihleri arası cam sera gece ve gündüz ortalama sıcaklık değerleri.

Figure 1. Average day and night temperature in glasshouse between 13-22/05/2017.

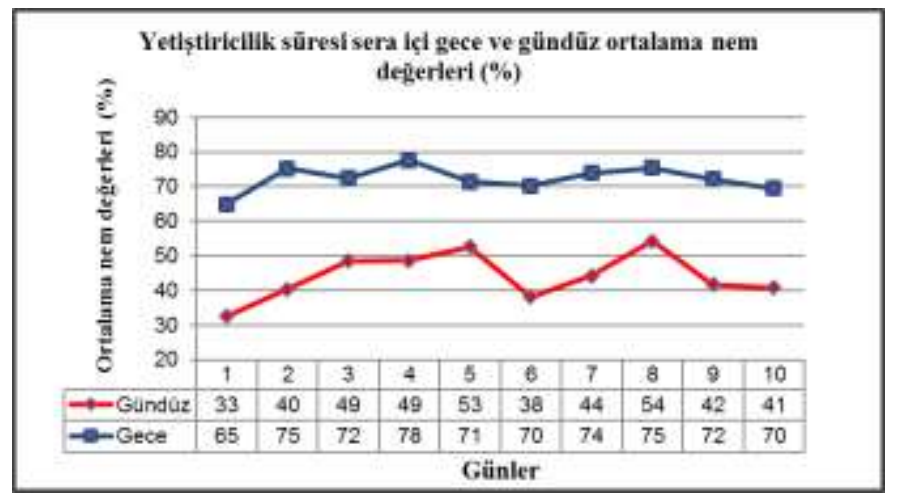

Şekil 2. Uygulamaların yapıldığı 13-22/05/2017 tarihleri arası cam sera gece ve gündüz ortalama nem değerleri.

Figure 2. Average day and night relative humidity in glasshouse between 13-22/05/2017. 
Çalışmada fide kök ve üst aksamlarında Azot, Potasyum, Fosfor, Kalsiyum, Demir, Magnezyum, Mangan ve Çinko içerikleri ile fide yapraklarında $\mathrm{H}_{2} \mathrm{O}_{2}$ miktarı belirlenmiştir.

$\mathrm{Bu}$ amaçla ögütülmüş kök ve üst aksam örneklerinden 0.5-2 g alınarak $\mathrm{HNO}_{3}$ ile mikrodalgada yakılmış örneklerden elde edilen çözeltilerde kalsiyum $(\mathrm{Ca})$, demir $(\mathrm{Fe})$, magnezyum $(\mathrm{Mg})$, mangan $(\mathrm{Mn})$, fosfor $(\mathrm{P})$, çinko $(\mathrm{Zn})$ ve potasyum $(\mathrm{K})$ miktarları ICP-OES (Inductively Coupled Plasma Optik Emisyon Spektrofotometre) cihazında analiz edilmiştir (NMKL 161 1998). Azot içeriği ise kök ve üst aksamda Leco FP-528 (protein analiz) cihazında belirlenmiştir (AOAC 1992).

Hidrojen peroksit $\left(\mathrm{H}_{2} \mathrm{O}_{2}\right)$ miktarının belirlenmesi için; her bir uygulamadan 6 fide seçilmiş ve her fide örneğinden $0.5 \mathrm{~g}$ taze yaprak alınarak $5 \mathrm{ml}$ soğuk \%0.1 TCA (Trikloroasetik Asit) içerisinde buz üzerinde havanda ezilerek homojenize edilmiş ve sonrasında $4^{\circ} \mathrm{C}$ 'de 10 dakika 10000 rpm'de santrifüj edilmiştir. Daha sonra elde edilen süpernatantın $0.75 \mathrm{ml}$ 'sine, sırasiyla $0.75 \mathrm{ml} 10 \mathrm{mM} \mathrm{KH} 2 \mathrm{PO}_{4}$ (pH: 7.0) tamponu ve $1.5 \mathrm{ml} 1 \mathrm{M} \mathrm{KI}$ eklenmiştir. Karışımın absorbansı Shimadzu UV-VIS 160 Spektrofotometrede $390 \mathrm{~nm}$ 'de okutulmuştur. $\mathrm{H}_{2} \mathrm{O}_{2}$ içeriği daha önce cihazda hazırlanan standart eğri yardımıyla $\mu \mathrm{M}$ (mikromol) olarak hesaplanmıştır (Velikova ark. 2000).

Araştırma 3 tekerrürlü ve her tekerrürde 15 fide olacak şekilde tesadüf parselleri deneme desenine göre kurulmuştur. İstatistiksel analizler Costat 6.3 programı ile yapılmış olup ortalamaların karşılaştırılmasında LSD Çoklu Karşılaştırma Testi $(P \leq 0.01,0.05)$ kullanılmıştır.

\section{Bulgular ve Tartışma}

\subsection{Patlican fidelerinde kök ve üst aksam Azot, Potasyum ve Fosfor içeriği}

Patlıcan fide köklerinde UV-B uygulamalarının azot miktarında istatistiksel olarak önemli bir değişikliğe neden olmadığı, düşük doz UV-B uygulamasına bağlı olarak üst aksamda azot içeriğinin arttığı belirlenmiştir. Kökte potasyum miktarının doz arttıkça arttığı saptanmış, üst aksamda potasyum miktarı UV-B uygulanan fidelerde azalmıştır. Yüksek doz UVB uygulaması kökte fosfor miktarında artışa neden olurken, düşük doz UV-B uygulaması üst aksamda fosfor içeriğini azaltııı etki yapmıştır (Çizelge 1).
Farklı büyüme evreleri boyunca UV-B'nin kışlık buğday verimi ve kalitesi üzerine etkilerini inceleyen Yao ark. (2014), buğdaylara bitki tepe noktasından $60 \mathrm{~cm}$ yükseklikte ve günlük 8 saat süreyle ilave $8.45 \mathrm{~m}^{-2} \mathrm{~d}^{-1}$ UV-B 1şın uygulaması yapmışlardır. Kontrol grubuna göre UV-B 1şın uygulanan bitkilerde azot, fosfor ve demir konsantrasyonu azalırken, mangan, çinko, bakır konsantrasyonu artmıştır, potasyum konsantrasyonun ise etkilenmediği bildirilmiştir. UV-B radyasyonunun artışı ile bitkinin besin elementi alınımının arttığını kaydetmişlerdir. UV-B'nin bitkilerdeki makro ve mikroelement konsantrasyonu üzerine etkisinin UV-B süresi ve dozuna göre değiştiği belirtilmiştir. Yüksek doz UV-B uygulaması sonucu patlıcan fidelerinin üst aksamında elde edilen azot içeriğinin araştırıcıların çalışmasına uyumlu olarak azaldığı görülmüştür. Araştırıcıların sonuçlarından farklı olarak yüksek doz UV-B uygulamasının patlıcan fidelerinin üst aksamlarında demir içeriğini arttırdığı saptanmıştır.

\subsection{Patlıcan fidelerinde kök ve üst aksam Kalsiyum, Demir ve Magnezyum içeriği}

Yüksek doz UV-B uygulaması patlıcan fide köklerinde kalsiyum, üst aksamda demir miktarını artırıcı etki yaparken uygulamaların üst aksam kalsiyum ve kökte demir miktarı üzerine bir etkisi olmadığı belirlenmiştir. Yüksek doz UV-B uygulaması kökte magnezyum içeriğinin artmasına sebep olurken, UV-B uygulamalarının patlıcan fidelerinin üst aksamlarında magnezyum içeriğinin düşmesine yol açtığ 1 belirlenmiştir (Çizelge 2).

Peng ve Zhou (2010) UV-B 1şın uygulamalarının soya fidelerinde kök, gövde ve yapraklardaki mineral elementlerin dağılımında değişiklik meydana getirdiğini, bunun da kuru madde birikiminin azalmasına ve daha sonra da büyümesinin engellenmesine yol açtığını bildirmişlerdir. Artan UV-B stresiyle kök, gövde ve yapraklarda potasyum, kalsiyum ve magnezyum içeriklerinde azalmalar görüldüğü, yapraklarındaki bakır, molibden ve demir içeriklerinde de azalmalar olurken mangan içeriğinin arttığı araştırmacılar tarafından bildirilmiştir. Patlıcan fidelerinin üst aksamlarında potasyum içeriği için elde edilen sonuçlar yukarıdaki araştırıcıların sonuçları ile uyum göstermektedir.

Çizelge 1. Farkı UV-B doz uygulamaların patlıcan fidelerinin kök ve üst aksamlarında azot, potasyum ve fosfor içeriği üzerine olan etkisi.

Table 1. The effect of different UV-B dose applications on the nitrogen, potassium and phosphorus content in the root and upper parts of eggplant seedlings.

\begin{tabular}{|c|c|c|c|c|c|c|}
\hline Uygulama Dozları & $\begin{array}{c}\text { Kökte Azot } \\
(\%)\end{array}$ & $\begin{array}{c}\text { Üst Aksamda Azot } \\
(\%)\end{array}$ & $\begin{array}{c}\text { Kökte Potasyum } \\
(\%)\end{array}$ & $\begin{array}{c}\text { Üst Aksamda Potasyum } \\
(\%)\end{array}$ & $\begin{array}{c}\text { Kökte Fosfor } \\
(\%)\end{array}$ & $\begin{array}{c}\text { Üst Aksamda Fosfor } \\
(\%)\end{array}$ \\
\hline Kontrol & 1.96 & $2.17 \mathrm{~b}$ & $1.44 \mathrm{c}$ & $3.86 \mathrm{a}$ & $0.79 \mathrm{~b}$ & $0.52 \mathrm{a}$ \\
\hline $10.8\left(\mathrm{~kJ} \mathrm{~m}^{-2}\right.$ gün $\left.^{-1}\right)$ & 2.32 & $3.56 \mathrm{a}$ & $1.80 \mathrm{~b}$ & $3.22 \mathrm{~b}$ & $0.74 \mathrm{~b}$ & $0.20 \mathrm{~b}$ \\
\hline $16.2\left(\mathrm{~kJ} \mathrm{~m}^{-2}\right.$ gün $\left.^{-1}\right)$ & 2.04 & $1.98 \mathrm{~b}$ & $2.50 \mathrm{a}$ & $3.31 \mathrm{~b}$ & $1.49 \mathrm{a}$ & $0.56 \mathrm{a}$ \\
\hline
\end{tabular}

LSD $\% 1$ (kök azot) $=$ Ö.D., LSD $\% 1$ (üst aksam azot) $=0.416$, LSD $\% 1$ (kök potasyum) $=0.129$, LSD $\% 1$ (üst aksam potasyum $)=0.471$, LSD $\% 1($ kök fosfor $)=0.245$, LSD $\% 1$ (üst aksam fosfor $)=0.078$.
ald 1 .

Çizelge 2. Farklı UV-B doz uygulamaların patlıcan fidelerinin kök ve üst aksamlarında kalsiyum, demir ve magnezyum içeriği üzerine olan etkisi.

Table 2. The effect of different UV-B dose applications on calcium, iron and magnesium content in the root and upper parts of eggplant seedlings.

\begin{tabular}{lccccc}
\hline Uygulama Dozları & $\begin{array}{c}\text { Kökte Kalsiyum } \\
(\%)\end{array}$ & $\begin{array}{c}\text { Üst Aksamda Kalsiyum } \\
(\%)\end{array}$ & $\begin{array}{c}\text { Kökte Demir } \\
(\mathrm{ppm})\end{array}$ & $\begin{array}{c}\text { Üst Aksamda Demir } \\
(\mathrm{ppm})\end{array}$ & $\begin{array}{c}\text { Kökte Magnezyum Üst Aksamda Magnezyum } \\
(\%)\end{array}$ \\
\hline Kontrol & $2.47 \mathrm{~b}$ & 1.61 & 16.83 & $62.32 \mathrm{~b}$ & $1.73 \mathrm{~b}$ \\
$10.8\left(\mathrm{~kJ} \mathrm{~m}^{-2}\right.$ gün $\left.^{-1}\right)$ & $2.33 \mathrm{~b}$ & 1.67 & 17.08 & $61.98 \mathrm{~b}$ & $5.39 \mathrm{a}$ \\
$16.2\left(\mathrm{~kJ} \mathrm{~m}^{-2}\right.$ gün $\left.^{-1}\right)$ & $2.69 \mathrm{a}$ & 1.70 & 18.10 & $75.28 \mathrm{a}$ & $2.65 \mathrm{~b}$ \\
\hline
\end{tabular}

LSD \%1 (kök kalsiyum) $=0.208$, LSD \%1 (üst aksam kalsiyum) $=$ Ö.D., LSD \%1 (kök demir)= Ö.D., LSD \%1 (üst aksam demir $)=10.91$, LSD \%1 (kök magnezyum) $=0.068$, LSD \%1 (üst aksam magnezyum) $=0.456$. 


\subsection{Patllcan fidelerinde kök ve üst aksam Mangan, Çinko ve $\mathrm{H}_{2} \mathrm{O}_{2}$ içeriğ $i$}

Patlıcan fidelerinin üst aksamlarında mangan miktarının uygulama dozuna bağlı olarak artış gösterdiği, köklerde ise bu artışın sadece yüksek doz UV-B uygulamasında görüldüğ̈̈ tespit edilmiştir. Düşük doz UV-B uygulaması kök ve üst aksamda çinko miktarını artırıcı etki gösterirken yüksek doz azaltıcı etkide bulunmuştur. $\mathrm{H}_{2} \mathrm{O}_{2}$ miktarı üzerine UV-B uygulamalarının patlıcan fidelerinde istatistiksel önemde bir etki yapmadığı belirlenmiştir (Çizelge 3 ).

Mullineaux ark. (2000) $\mathrm{H}_{2} \mathrm{O}_{2}$ 'in patojen-indüklü tepkiler esnasında olduğu gibi abiyotik stresler esnasında da bir sinyal molekülü olarak işlev gördüğünü bildirmişlerdir. Süperoksit radikalleri $\left(\mathrm{O}_{2}^{-}\right)$, oksidatif metabolizmanın toksik yan ürünleridir ve $\mathrm{H}_{2} \mathrm{O}_{2}$ ile tepkimeye girerek, hücrelerdeki oksijen toksisitesinden birincil derecede sorumlu olan yüksek reaktif hidroksil radikallerini ( $\mathrm{OH})$ oluşturur (Bowler ark. 1992). $\mathrm{O}_{2}^{-}$nin $\mathrm{H}_{2} \mathrm{O}_{2}$ ve oksijene dismutasyonu, hücreyi korumada ilk adımdır (de Azevedo ark. 2005). Antioksidan enzimler, oksidatif hasarı hafifletmek için ROS (reaktif oksijen türleri) süpürücüleri olarak rol oynamaktadır. SOD (süperoksit dismutaz), süperoksit radikalle $\mathrm{H}_{2} \mathrm{O}_{2}$ üretmek üzere reaksiyona girmekte ve $\mathrm{H}_{2} \mathrm{O}_{2}$ 'de APX (askorbat peroksidaz) ve CAT (katalaz) başta olmak üzere peroksidazlar tarafindan süpürülmektedir (Miller ark. 2010). Bitkilerde UV-B radyasyonuna yanıt olarak tür içi ve türler arasında büyüme, kuru madde üretimi, fizyolojik ve biyokimyasal değişimler bakımından büyük farklılıklar rapor edilmiştir (Fedina ark. 2010).
Uygulamada kullanılan UV-B ışınının patlıcan fidelerinde $\mathrm{H}_{2} \mathrm{O}_{2}$ içeriğine etki etmemesine neden olarak doz ve/veya uygulama sürelerinin fidelerde stres oluşturacak miktarda olmadığı ya da CAT (Katalaz) enzim aktivitesinin $\mathrm{H}_{2} \mathrm{O}_{2}$ miktarına azaltıcı etki yaptığı düşünülebilir.

Correia ark. (2012) UV-B stresi altında mısır yapraklarında fosfor, azot, bakır, çinko ve mangan konsantrasyonunun azaldığını rapor etmişlerdir. Sonuçlar patlıcan fidelerinde yüksek doz UV-B uygulaması çinko içeriği için yukarıdaki araştırıcıların çalışması ile uyum göstermektedir.

\section{Sonuç}

Stres faktörlerini kullanarak fidelerde korunma mekanizmasını uyarmak, bu şekilde dayanıklılığı artırmak fidecilik sektöründe kimyasal uygulamalarına alternatif olarak son yıllarda önemli hale gelmiştir. Bir stres faktörü olan UV-B 1şın uygulamalarının fide gelişimi ve kalitesi üzerine etkileri bu anlamda değer kazanmıştır.

Düşük doz UV-B uygulaması patlıcan fidelerinin kök ve üst aksamlarında çinko miktarını artırmış, azot miktarındaki artış ise sadece üst aksamda görülmüştür. Yüksek doz uygulamasında ise kök ve üst akşamlarda kalsiyum, mangan ve fosfor içeriklerinin arttığı; bu artışın sadece kökte potasyum, magnezyum ve üst aksamda da demir için olduğu saptanmıştır.

Fidelerde bazı minerallerin içeriğine olan etkisi nedeniyle, ultraviyole-B 1şın uygulamasının dozlara ve türlerin dozlara verdiği tepkiye bağlı olarak fide sektöründe fide kalitesine olumlu etki edebileceği düşünülmektedir.

Çizelge 3. Farklı UV-B doz uygulamaların patlıcan fidelerinin kök ve üst aksamlarında mangan, çinko ve fide yapraklarında $\mathrm{H}_{2} \mathrm{O}_{2}$ içeriği üzerine olan etkisi.

Table 3. The effect of different UV-B dose applications on manganese, zinc and $\mathrm{H}_{2} \mathrm{O}_{2}$ in the root and upper parts of eggplant seedlings.

\begin{tabular}{lcccc}
\hline Uygulama Dozları & $\begin{array}{c}\text { Kökte Mangan } \\
(\mathrm{ppm})\end{array}$ & $\begin{array}{c}\text { Üst Aksamda Mangan } \\
(\mathrm{ppm})\end{array}$ & $\begin{array}{c}\text { Kökte Çinko } \\
(\mathrm{ppm})\end{array}$ & $\begin{array}{c}\text { Üst Aksamda Çinko }_{(\mathrm{ppm})} \\
\begin{array}{c}\mathrm{H}_{2} \mathrm{O}_{2} \\
(\mu \mathrm{M})\end{array}\end{array}$ \\
\hline Kontrol & $25.93 \mathrm{~b}$ & $62.90 \mathrm{c}$ & $46.18 \mathrm{~b}$ & $22.02 \mathrm{ab}$ \\
$10.8\left(\mathrm{~kJ} \mathrm{~m}^{-2}\right.$ gün $\left.^{-1}\right)$ & $23.82 \mathrm{~b}$ & $86.01 \mathrm{~b}$ & $54.99 \mathrm{a}$ & $26.65 \mathrm{a}$ \\
$16.2\left(\mathrm{~kJ} \mathrm{~m}^{-2} \mathrm{gün}^{-1}\right)$ & $5228 \mathrm{a}$ & $100.88 \mathrm{a}$ & $25.56 \mathrm{c}$ & 0.06 \\
\hline
\end{tabular}

LSD $\% 1$ (kök mangan) $=2.824$, LSD $\% 1$ (üst aksam mangan) $=9.54$, LSD $\% 1($ kök çinko $)=6.70$, LSD $\% 1($ üst aksam çinko $)=11.59$, LSD $\% 1\left(\mathrm{H}_{2} \mathrm{O}_{2}\right)=$ Ö.D. .

\section{Teşekkür}

$\mathrm{Bu}$ araştırma yüksek lisans tez çalışmasındaki verilerin bir kısmından oluşmaktadır. Desteklerinden dolayı Akdeniz Üniversitesine teşekkür ederiz.

\section{Kaynaklar}

Anderson JG, Toohey DW, Brune WH (1991) Free radicals within the antarctic vortex: The role of cfcs in antarctic ozone loss. Science 251(4989): 39-46.

AOAC (1992) Crude Protein in Cereal Grains and Oilseeds. Official Method 992.23.

Bowler C, Montagu M, Inze D (1992) Superoxide dismutase and stress tolerance. Annual Review of Plant Biology 43: 83-116.

Correia CM, Coutinho JF, Bacelar EA, Gonçalves BM, Bjorn LO, Pereia JM (2012) Ultraviolet-B radiation and nitrogen affect nutrient concentrations and the amount of nutrients acquired by above-ground organs of maize. Science World Journal 1: 11.

de Azevedo Neto AD, Prisco JT, Eneas-Filho J (2005) Hydrogen peroxide pretreatment induces salt-stress acclimation in maize plants. Journal of Plant Physiology 162: 1114-1122.
Fedina I, Hidema J, Velitchkova M, Georgieva K, Nedeva D (2010) UV-B induced stress responses in three rice cultivars. Biologia Plantarum 54: 571-574.

Li Z, Zhang Y, Peng D, Wang X, Peng Y, He X, Zhang X, Ma X, Huang L, Yan Y (2015) Polyamine regulates tolerance to water stress in leaves of white clover associated with antioxidant defense and dehydrin genes via involvement in calcium messenger system and hydrogen peroxide signaling. Front Physiol 6: 280. doi: 10.3389/fphys.2015.00280.

Miller GAD, Suzuki N, Ciftci-Yilmaz S (2010) Reactive oxygen species homeostasis and signalling during drought and salinity stresses. Plant Cell Environ 33(4): 453-67.

Mullineaux P, Bali L, Escobar C, Karpinska B, Creissen G, Karpinski S (2000) Arediverse signaling pathways integrated in the regulation of Arabidopsis antioxidant defense gene expression in response to excess excidation energy. Philosophical Transsactions of Royal Society London 355: 1531-1540.

NMKL 161 (1998) Metals determination by atomic absorption spectrophotometry after wet digestion in a microwave oven (Codex Endorsed Method).

Oktay M (1999) Çinko katkılı kompoze gübrelerin değişik kültür bitkilerinin yetiștiriciliğinde kullanım. Ege Üniversitesi, Tarımsal Uygulama ve Araştırma Merkezi Yay. No: 35, İzmir. 
Peng Q, Zhou Q (2010) Effects of enhanced UV-B radiation on the distribution of mineral elements in soybean (Glycine Max) seedlings. Chemosphere 78(7): 859-863.

Velikova V, Yordanow I, Edreva A (2000) Oxidative stress and some antioxidant systems in acid rain treated bean plants protective role of exogenous polyamines. Plant Science (151): 59-66.

Vural H, Eşiyok D, Duman İ (2000) Kültür Sebzeleri (Sebze Yetiştirme). Ege Üniversitesi, Ziraat Fakültesi, Bahçe Bitkileri Bölümü. Bornova, İzmir.

Yao X, Chu J, He X, Si C (2014) Grain yield, starch, protein and nutritional element concentrations of winter wheat exposed to enhanced UV-B during different growth stages. Journal of Cereal Science 60: 31-36.

Yaşar F (2003) Tuz stresi altındaki patlıcan genotiplerinde bazı antioksidant enzim aktivitelerinin in vitro ve in vivo olarak incelenmesi (doktora tezi, basılmamıs). Yüzüncü Yıl Üniversitesi. Fen Bilimleri Enstitüsü, Van, s. 139.

Yuan L, Ming Y, Xunling W (1998) Effects of enhanced ultraviolet-B radiation on crop structure, Growth and yield components of spring wheat under field conditions. Field Crops Research 57(3): 253-263. 